\title{
Comparative Study of Industrial Lignosulfonates and Some Their Properties
}

Brigita Neiberte

Latvian State Institute of Wood Chemistry,

27 Dzerbenes St., Riga, LV-1006, Latvia.

Anrijs Verovkins

Latvian State Institute of Wood Chemistry,

27 Dzerbenes St., Riga, LV-1006, Latvia.
Antons Jablonsky

Latvian State Institute of Wood

Chemistry,

27 Dzerbenes St., Riga, LV-1006, Latvia.

Sanita Vitolina

Latvian State Institute of Wood Chemistry,

27 Dzerbenes St., Riga, LV-1006, Latvia.
Galia Shulga

Latvian State Institute of Wood

Chemistry,

27 Dzerbenes St., Riga, LV-1006, Latvia.

Julia Brovkina

Latvian State Institute of Wood Chemistry,

27 Dzerbenes St., Riga, LV-1006, Latvia.

\begin{abstract}
The aim was to compare the chemical composition and some properties of three industrial lignosulfonates produced as a by-product at three pulp and paper mills (Russia). Using the classical methods of lignin chemistry, it was found that there were differences in the elemental composition and the content of functional groups of the industrial lignosulfonates, but in general, they were not very significant. The Kondopoga lignosulfonates contained the highest content of methoxy, aliphatic hydroxyl groups and carbonyl groups. The Vyborg lignosulfonates had the highest degree of sulfonation and the lowest content of carbonyl groups. The content of the functional groups in the chemical composition of the Syassky lignosulfonates was intermediate between the functional composition of the Vyborg and Kondopoga lignosulfonates. The Vyborg lignosulfonates had the lowest values of the viscosity average molecular mass, dynamic viscosity and surface tension at the air-water interface in comparison with these parameters of the Kondopoga and Syassky lignosulfonates.
\end{abstract}

Keywords-industrial lignosulfonates, composition, viscosity, surface tension

\section{INTRODUCTION}

According to the strategy and principles of the Circular Economy, great attention has to be drawn to the rational and effective utilization of biomass by-products because this provides a huge secondary resource for producing new materials and reduces their costs.

Lignosulfonates are available on the global market as a by-product of pulp and paper mills producing cellulose. They can be regarded as a special class of industrial lignins that are used for production of materials and chemical applications [1].

Due to their availability, physicochemical properties and low price, lignosulfonates are used for obtaining binders, emulsifiers, dust suppressants, dispersants and soil improvers. Their ability to coagulate and precipitate proteins is used in water purification of wastewater from meat and fish canneries or milk processing plants. As an anti-settling agent, lignosulfonates are used in concrete mixtures, ceramics, gypsum board production and for leather tanning. Lignosulfonates provide flowability

and plasticity to cement. Lignosulfonates can be used in polymeric blends as an additive or a filler for obtaining new composite materials $[2,3]$.

On the other hand, the achievements of remarkable results in application of lignosulfonates require a deeper knowledge of their chemical composition and properties, which may help overcome their drawbacks and exploit their advantages.

The aim of the work was to compare the chemical composition and some properties of three industrial lignosulfonates produced as a by-product at three pulp and paper mills (Russia).

\section{Materials AND METHODS}

For the study, we used three industrial lignosulfonates, obtained as a result of producing cellulose by the sulfite method at three Russian mills, namely, JSC Kondopoga (Kondopoga Pulp and Paper Mill), JSC Syassky Pulp and Paper Mill and OJSC "Vyborg Cellulose". Industrial lignosulfonates were used in a powder form and were stored in a desiccator with $\mathrm{P}_{2} \mathrm{O}_{5}$. The content of reducing substances in the lignosulfonates did not exceed $10 \%$. Their main characteristics corresponded to TU 2455-02800279580-2004 (Russia). Methods for determining the content of functional groups and ash in lignosulfonates are given in a concise form and are described in detail in [4-6].

Determination of methoxy groups by the ZeiselVebock-Schwappack method. The content of methoxy groups $\left(-\mathrm{OCH}_{3}\right)$ is an essential criterion for the characterization of the lignin content in a sample. The methoxy groups' content was determined by the ZeiselVebock-Schwappack method using the test sample treatment with $57 \%$ concentrated $\mathrm{HJ}$ at a temperature of $140{ }^{\circ} \mathrm{C}$ during $30 \mathrm{~min}$.

Determination of the sulfo and phenolic hydroxyl groups. The conductometric titration method was applied for the quantitative determination of the sulfo groups $\left(-\mathrm{SO}_{3} \mathrm{H}\right)$ and phenolic hydroxyl groups $\left(\mathrm{OH}_{\text {phen }}\right)$ in lignosulfonate samples. For this purpose, an automatic 
"Radiometer analytical" titration device CDM 210 Meter Lab was used.

Determination of the total acidic hydroxyl groups. The hemosorption method is based on the ion exchange reactions between the substance's acidic groups $\left(\mathrm{OH}_{\text {phen }}+\mathrm{OH}_{\mathrm{COOH}}\right)$ and $\mathrm{Ba}(\mathrm{OH})_{2}$ or $\left(\mathrm{CH}_{3} \mathrm{COO}\right)_{2} \mathrm{Ca}$. The tested sample was suspended in $0.1 \mathrm{M} \mathrm{LiOH}$ (or $\mathrm{NaOH}$ ) solution and heated at $85{ }^{\circ} \mathrm{C}$; then the relevant amount of $\mathrm{BaCl}_{2}$ solution was added. The chemical equilibrium was shifted, creating insoluble salts. The strong acidic groups were determined by the treatment of the sample with $\mathrm{CH}_{3} \mathrm{COOCa}$.

Determination of the total aliphatic and phenolic hydroxyl groups. A Freudenberg method is based on the quantitative reaction between lignin's hydroxyl groups and acetic anhydride in the presence of pyridine as a catalyst.

Determination of carbonyl groups. Lignin's carbonyl groups are presented as ketone groups $\mathrm{R}_{2} \mathrm{C}=\mathrm{O}$ or aldehyde groups $\mathrm{RHC}=\mathrm{O}$, which, in the reaction with hydroxylamine hydrochloride solution, attract it in an equivalent amount by releasing $\mathrm{HCl}$. The amount of the released $\mathrm{HCl}$ was determined by potentiometric or conductometric titration with $0.1 \mathrm{M}$ alkaline solution.

Determination of the mineral (ash) content. The tested sample was burnt in a muffle oven at a temperature of 525 $600{ }^{\circ} \mathrm{C}$ using a previously weighed and heated porcelain crucible. The sample was kept at this temperature during 3-4 hours.

Elemental analysis. The LS elemental composition $(\mathrm{C}, \mathrm{H}, \mathrm{S}, \mathrm{N})$ was determined by an element analyzer Vario Macro CHNS Elementar Analysensysteme GmbH (Germany).

FTIR spectroscopy. Fourier-transform infrared spectroscopy (FTIR) was carried out using a spectrophotometer (Perkin-Elmer Spectrum One, USA) with $\mathrm{KBr}$ tablets.

Determination of molecular mass. To determine the average molecular mass of lignosulfonates, the viscometric method was used, using $0.1 \mathrm{M} \mathrm{NaCl}$ water solution as a solvent. Molecular masses were found using the Mark-Houwink-Kun equation [7]. Three replicates were made for each LS sample.

Surface tension. The surface tension $(\sigma)$ of LS water solutions at the water-air interface was measured by a Wilhelmy plate, using a tensiometer K100M (KRUSS, Germany) at $25{ }^{\circ} \mathrm{C}$ with a circulation thermostat. The preparation of the samples and the measuring procedure were similar to those described in [8]. Three replicates were made for each sample.

Viscometry. Specific viscosity ( $\eta$ ) was determined using a capillary viscometer Ubelhode with the flow time of pure water close to $300 \pm 0.01 \mathrm{sec}$ at $25.0 \pm$ $0.1{ }^{\circ} \mathrm{C}$ similar to that described in [8], as well as a digital viscometer (Brookfield Engineering Laboratory, USA). Three replicates were made for each sample.

\section{Results AND Discussion}

Lignosulfonates are water-soluble salts of lignosulfonic acids with impurities of reducing and mineral substances, formed during the sulfite process of wood delignification. It is known that three main reactions occur in the sulfite cooking process - lignin sulfonation, its hydrolysis and condensation, which are accompanied by the oxidation of lignin, its dehydration, sulfidation, etc. In addition, industrial lignosulfonates contain hemicelluloses, which are chemically bonded to lignin due to ester bonds, as well as metal ions that are presented by ash. All these chemical conversions affect the molecular mass, chemical composition and properties of the resulting lignosulfonates.

Tables 1 and 2 show the results of the elemental and chemical analysis of three industrial lingo-sulfonates obtained at the JSC Kondopoga (Kondopoga LS), the JSC Syassky Pulp and Paper Mill (Syassky LS), and the OJSC "Vyborg Cellulose" (Vyborg LS).

TABLE 1.

CONTENT OF ELEMENTS, METHOXY GROUPS AND ASH IN LIGNOSULFONATES

\begin{tabular}{cccccccc}
\hline Ligno-sulfonates & $\begin{array}{c}\text { Ash, } \\
\%\end{array}$ & {$\left[-\mathrm{OCH}_{3}\right], \%$} & $\begin{array}{c}\mathrm{C}, \\
\%\end{array}$ & $\begin{array}{c}\mathrm{H}, \\
\%\end{array}$ & $\begin{array}{c}\mathrm{O}, \\
\%\end{array}$ & $\begin{array}{c}\mathrm{S}, \\
\%\end{array}$ & $\begin{array}{c}\mathrm{N}, \\
\%\end{array}$ \\
\hline Kondopoga & 17.21 & 8.78 & 41.53 & 3.68 & 47.84 & 6.95 & 0.25 \\
Syassky & 16.54 & 7.93 & 41.65 & 3.86 & 47.34 & 7.15 & 0.32 \\
Vyborg & 19.75 & 6.98 & 41.88 & 3.89 & 45.65 & 7.92 & 0.66 \\
\hline
\end{tabular}

According to the conducted chemical analysis, there are differences in the elemental composition and the content of the functional groups of the studied lignosulfonates, but in general, they are not very significant. It can be seen that Kondopoga LS contain more methoxy groups $8.78 \%$, aliphatic and phenolic hydroxyl groups $-8.96 \%$, as well as carbonyl groups $-3.48 \%$ that is almost 2.3 and 1.5 times higher than their content in Vyborg LS and Syassky LS, respectively. At the same time, Vyborg LS have the highest degree of sulfonation, expressed in a high content of sulfo groups $-5.75 \%$, which is $25 \%$ higher than the content of these groups in Syassky LS and Kondopoga LS.

TABLE 2.

CONTENT OF ACIDIC HYDROXYL, ALIPHATIC AND SULFO GROUPS IN LIGNOSULFONATES

\begin{tabular}{|c|c|c|c|c|c|c|}
\hline LS & $\begin{array}{c}{\left[\mathrm{SO}_{3} \mathrm{H}\right],} \\
\%\end{array}$ & $\begin{array}{c}{[\mathrm{OH}]} \\
\% \\
\text { aliphatic } \\
+ \text { phenolic }\end{array}$ & $\begin{array}{c}{[\mathrm{OH}]} \\
\% \\
\text { phenolic }\end{array}$ & $\begin{array}{c}{[\mathrm{OH}]} \\
\% \\
\text { aliphatic }\end{array}$ & $\begin{array}{c}{[\mathrm{OH}]} \\
\% \\
\text { phenolic } \\
+ \text { carboxyl }\end{array}$ & $\begin{array}{c}{[\mathrm{CO}]} \\
\%\end{array}$ \\
\hline Kondopoga & 4.56 & 8.96 & 2.88 & 6.08 & 5.92 & 3.48 \\
\hline Syassky & 4.59 & 6.35 & 2.82 & 3.53 & 6.41 & 2.36 \\
\hline Vyborg & 5.75 & 7.24 & 2.28 & 4.96 & 6.97 & 1.49 \\
\hline
\end{tabular}

The chemical composition of Vyborg LS is characterized by the highest content of acidic hydroxyl groups, represented by phenolic hydroxyl and carboxyl groups, and the lowest content of carbonyl groups of $1.49 \%$ compared to the other

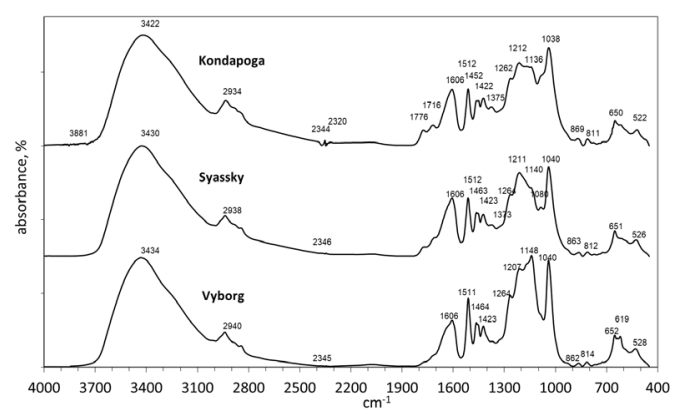

Fig. 1. FTIR spectra of Kondopoga LS, Syassky LS and Vyborg LS 
Samples of lignosulfonates. It should be noted that Syassky LS contain the lowest amount of aliphatic hydroxyl groups $-3.53 \%$, while the content of other functional groups in Syassky LS is intermediate between the functional composition of Vyborg LS and Kondopoga LS.

For more information about the functional composition of the technical lignosulfonates, the FTIR method was used. The obtained FTIR spectra of Kondopoga LS, Syassky LS and Vyborg LS are presented in Fig. 1. A qualitative comparison of the spectra shows that the lignosulfonates of various productions have insignificant differences in the functional composition. The presence of two absorption peaks at $1776 \mathrm{~cm}^{-1}$ and $1715 \mathrm{~cm}^{-1}$ due to the stretching vibrations of carbonyl groups in the aromatic and aliphatic structures of lignin [9] in the FTIR spectrum of Kondopoga LS confirms the increased content of carbonyl groups in their functional composition in comparison with Syassky LS and Vyborg LS, whose FTIR spectra in this region contain weakly pronounced these absorption bands. The absorption bands in the region of $1160-1030 \mathrm{~cm}^{-1}$ are attributed to the planar deformation vibrations of $\mathrm{C}-\mathrm{H}$ bonds in syringyl and guaiacyl derivatives of lignin [9]. A different ratio of the intensity of the absorption bands at $1148 \mathrm{~cm}^{-1}$ and $1040 \mathrm{~cm}^{-1}$ in the FTIR spectrum of Vyborg LS relative to the intensity ratio of the bands at $1140 \mathrm{~cm}^{-1}$ and $1040 \mathrm{~cm}^{-}$ ${ }^{1}, 1136 \mathrm{~cm}^{-1}$ and $1038 \mathrm{~cm}^{-1}$ in the FTIR spectra of Syassky LS and Kondopoga LS, respectively, may be caused by the different content of these derivatives in the industrial lignosulfonates and may be confirmed by the different amount of methoxy groups in the samples. The presence of two absorption bands at $652 \mathrm{~cm}^{-1}$ and $619 \mathrm{~cm}^{-1}$, which are attributed to the sulfo groups in lignosulfonates [2], in the FTIR spectrum of Vyborg LS, is in agreement with the increased degree of sulfonation of this lignin sample.

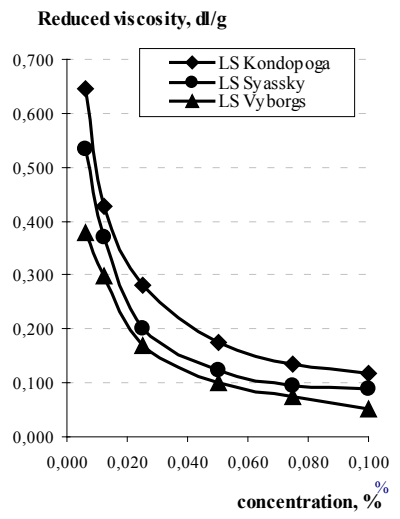

Fig. 2. Reduced viscosity of lignosulfonates depending on their concentration

The effectiveness of the practical application of lignosulfonates is determined by their properties. Fig. 2 shows the curves of the reduced viscosity of the dilute aqueous solutions of lignosulfonates depending on their concentration. It is seen that, with decreasing concentration, the reduced viscosity of lignosulfonates increases dramatically due to the presence of the polyelectrolyte effect that is caused by the ionogenic nature of these industrial lignins containing strong sulfo and weak acidic groups such as phenolic hydroxyl and carboxyl ones in their phenylpropane chains. Determination of the average molecular masses of lignosulfonates by viscometry, using the Mark-Houwink-Kun equation for their calculation, showed that Kondopoga LS with the lowest degree of sulfonation and the highest content of methoxy groups, compared to the same indicators for Syassky LS and Vyborg LS, had the highest viscosity average molecular weight equal to 41,300 Da. Vyborg LS, characterized by the highest content of sulfo groups and the lowest content of methoxy groups, had the lowest molecular mass of $34,700 \mathrm{Da}$. The value of the viscosity average molecular mass of Syassky LS was close to that of the molecular mass of Vyborg LS, to be 36,500 Da.

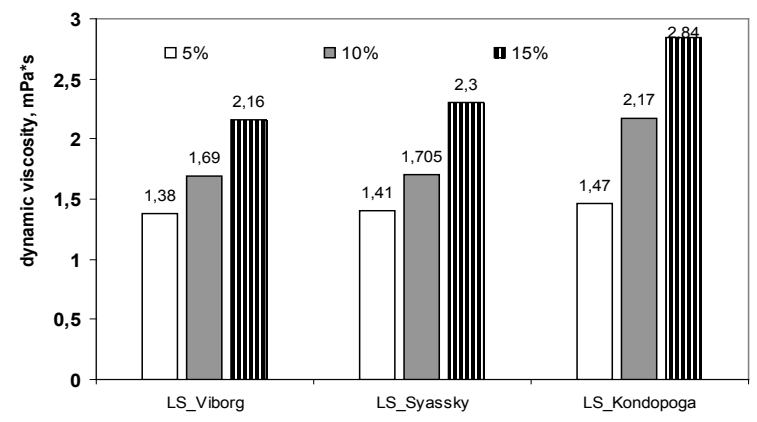

Fig. 3. Dynamic viscosity of lignosulfonates; $\mathrm{pH} 5.0$

Figure 3 shows the dynamic viscosity values of moderately concentrated solutions of the technical lignosulfonates, determined with a rotational viscometer. It can be seen that, with increasing concentration from 5 to $15 \%$, the dynamic viscosity of lignosulfonates increases 1.5-2.0 times and achieves 2.2-2.8 mPa*s. Kondopoga LS are characterized by the highest values of dynamic viscosity. It can be assumed that the higher viscosity average molecular mass of Kondopoga LS, compared with the molecular masses of Syassky LS and Vyborg LS, is the main reason for their higher values of dynamic viscosity. It is known that lignosulfonates are often used to obtain biodegradable and non-toxic emulsifiers and dispersants based on their good surface active properties. The surface activity of technical lignosulfonates from the different pulp and paper mills can be evaluated by measuring their surface tension $(\sigma)$ against their concentration.

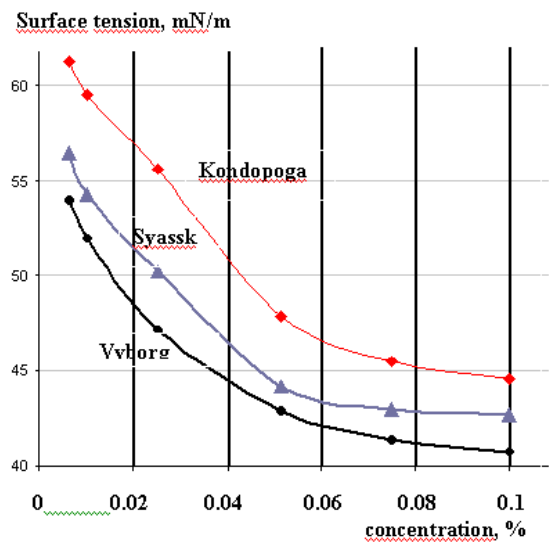

Fig. 4. Surface tension of diluted solutions of lignosulfonates at the air-water interface; $\mathrm{pH} 5.0 ; 22{ }^{\circ} \mathrm{C}$ 
Figure 4 shows the surface tension isotherms at the air-water interface for $0.01-0.1 \%$ lignosulfonates water solutions at $\mathrm{pH}$ 5.0. As can be seen, surface tension is dependent on the lignin concentration and, with its increasing, the surface tension at the interface decreases. The measured values of the surface tension at the airwater interface vary from $62-54 \mathrm{mN} / \mathrm{m}$ to $45-41 \mathrm{mN} / \mathrm{m}$ for 0.01-0.1\% lignosulfonates water solutions, respectively, and are aligned as Kondopoga LS > Syassky LS > Vyborg LS. It is known that the ability to be adsorbed at the air-water interface, along with the solution environment, is determined by the features of the lignin molecular structure, including the molecular mass values and chemical composition, affecting their hydrophilichydrophobic balance. Evidently, the highest content of carbonyl groups and a higher dynamic viscosity of Kondopoga LS cause a lower surface activity of these lignosulfonates in comparison with Syassky LS and Vyborg LS. On the other hand, Vyborg LS, containing the lowest content of carbonyl groups and having a lower dynamic viscosity, has the enhanced surface activity at the air-water interface.

\section{CONCLUSION}

The comparative chemical analysis of three industrial lignosulfonates from the Kondopoga, Syassky and Vyborg pulp and paper mills was performed. It was found that the Kondopoga lignosulfonates contained the highest content of methoxy, aliphatic hydroxyl groups and carbonyl groups. The Vyborg lignosulfonates had the highest degree of sulfonation and the lowest content of carbonyl groups. The content of the functional groups in the chemical composition of the Syassky lignosulfonates was intermediate between the functional composition of the Vyborg and Kondopoga lignosulfonates. The Vyborg lignosulfonates had the lowest values of the viscosity average molecular mass, dynamic viscosity and surface tension at the air-water interface in comparison with these indexes of the Kondopoga and Syassky lignosulfonates.

\section{ACKNOWLEDGMENTS}

The authors have received funding for this study from the Forest Sector Competence Centre of Latvia (P2 project, No. KC/2.1.2.1.1/10/01/003).

\section{REFERENCES}

[1] Qian Y., Lou H., Liu W., Yang D., Ouyang X., Li Y., Qiu X. Lignin - a promising biomass resource, TAPPI JOURNAL, March 2018.

[2] Sarkanen K. V., Ludwig C. H., Lignins, Occurrence, Formation, Structure and Reactions. Wiley Interscience, New York, 1971.

[3] Lignin: Structural Analysis, Applications in Biomaterials and Ecological Significance. Fachuang Lu (Ed), Nova Publishers, New York, 2014.

[4] Zakis G. F. Functional analysis of lignins and their derivatives. Atlanta: TAPPI PRESS, GA: 1994.

[5] David N.-S., Shiraishi Hon Nobuo. Wood and cellulosic chemistry, second edition. New York: Marcel Dekker, 2001, 931.p.

[6] Fengel D., Wegener G. Wood Chemistry. Verlag Kessel: 2003, $611 \mathrm{p}$.

[7] Yean G.W., Rezanowich A., Goring D.A.I. The molecular weight and configuration of sodium lignosulphonate from spruce wood. In: Chemistry and Biochemistry of Lignin, Cellulose and Hemicelluloses. M.N. Cipkina (Ed). Moscow, 1969, pp.158-169.

[8] Shulga G., Shakels V., Aniskevicha O., Bikova T., Treimanis A. Effect of alkaline modification on viscometric and surface-active properties of soluble lignin. Cell. Chem. Techn., 40, 2006, pp. 383-392.

[9] Ahvazi B., Cloutier É., Wojciechowicz O., Ngo T.D. Lignin Profiling: A Guide for Selecting Appropriate Lignins as Precursors in Biomaterials Development. ACS Sustainable Chem. Eng., 2016, 4 (10), pp 5090-5105. 